Cipango Cahiers d'études japonaises

$20 \mid 2013$

Nouveaux regards sur les arts de la scène japonais I

\title{
La nuit dans la nuit (1993)
}

\section{Miri Yū}

Traducteur : Toshio Takemoto

\section{OpenEdition}

Journals

\section{Édition électronique}

URL : https://journals.openedition.org/cipango/1972

DOI : $10.4000 /$ cipango.1972

ISSN : 2260-7706

\section{Éditeur}

INALCO

Édition imprimée

Date de publication : 30 octobre 2013

ISSN : 1164-5857

\section{Référence électronique}

Miri Yū, « La nuit dans la nuit (1993) », Cipango [En ligne], 20 | 2013, mis en ligne le 17 avril 2015

consulté le 30 juin 2021. URL : http://journals.openedition.org/cipango/1972 ; DOI : https://doi.org/ 10.4000/cipango.1972

Ce document a été généré automatiquement le 30 juin 2021.

\section{(c) $(1)(9)$}

Cipango est mis à disposition selon les termes de la Licence Creative Commons Attribution - Pas d'Utilisation Commerciale 4.0 International. 


\section{La nuit dans la nuit (1993)}

\section{Miri Yū}

Traduction : Toshio Takemoto

\section{NOTE DE L'AUTEUR}

Yū Miri 柳美里, «Yoru no naka no yoru » 夜の中の夜, in Sakana ga mita yume 魚が見た 夢 (le Rêve du poisson), (2000), 2003, Shinchōsha 新潮社, p. 111-114.

Parfois, ma voix se rouille.

Le téléphone sonne, je ne peux décrocher le combiné. Mon cœur bat tant la chamade que le sang bat dans mes tempes. Des mots, des mots, de multiples mots s'envolent en tous sens dans ma tête, tels des draps dans une sécheuse. Avant que je ne me décide à prendre le combiné, le téléphone se calme. Je vais bientôt détester comme un ennemi personnel ce téléphone qui est au coin de la pièce. J'oublie sciemment de payer la facture pour que l'abonnement téléphonique expire.

Il m'arrive de détester les rendez-vous au point d'avoir envie de mourir. Coincés à une table de café, fumant comme des pompiers, nous entretenons un dialogue de sourds. Mon propos, celui de mon interlocuteur, me passent tout près de l'oreille, tel le murmure d'un ruisseau. Dans mes oreilles n'entre aucun mot. Je bois du thé glacé trop dilué à cause des glaçons qui fondent, mon interlocuteur baisse un regard évasif sur sa montre. Quand je sors, seule, du café, pareille à du métal chauffé et fondu, je suis en colère contre moi, mais mon exaspération diminue, s'aiguise en se durcissant et me transperce le cœur. Quand je contemple d'un regard en dents de scie les visages des gens qui se croisent aux carrefours, les visages des gens qui se tiennent aux poignées du métro, ils me paraissent les uns et les autres si laids et si futiles que j'ai envie de me crever les yeux pour tout plonger dans les ténèbres. Alors je tente d'avancer en suivant le plus possible le flot de la foule. Vêtu d'un costume qui lui tombe juste, un employé de bureau marche d'un pas régulier. Le contour de son dos est aussi net que l'exercice de maths que j'ai résolu avec un crayon $2 \mathrm{H}$ au collège. Le contour du dos du vagabond qui traîne en ramassant quelque chose paraît difforme et flou comme un mauvais croquis 
sur papier cartonné. Quand je regarde le dos de quelqu'un, je me sens moins en colère et agacée contre moi-même.

4 C'est pourquoi j'adore les sièges du tout dernier rang au théâtre. L'air du théâtre, au cri du comédien, devient blanc, le dos du spectateur assis devant moi bouge à peine. Là, son voisin se crispe et lève la tête, un spectateur assis derrière lui baisse la tête bien bas. L'un se met à trembler des épaules, l'autre à regarder tout autour.

5 N'y aurait-il pas des fils invisibles partout dans un théâtre ? Quelqu'un touche-t-il ce fil invisible, ce fil touché touche alors toutes les personnes présentes au théâtre. Je m'ébranle dans cette agitation sans paroles, j'observe toujours le dos du spectateur, j'imagine en secret ce qu'il ressent.

6 J'adore les ténèbres du théâtre.

7 Quand toutes les scènes de la pièce que j'ai écrite sont finies, et que toutes les lumières s'éteignent, j'ai l'impression que l'on m'enferme vivante dans un cercueil au fond duquel les ténèbres s'étendent à l'échelle du cosmos, c'est horrible ! On cite le cas d'un certain type de malade mental qui, persuadé d'être sur un point minuscule de l'espace étendu à l'infini, ressent vraiment la peur et le vide, et mon sentiment ressemble beaucoup à ça. La différence, c'est que je crois voir, dans les ténèbres du théâtre, la nature vraie des choses qui se cachent au fond de mon cœur. Tel est le paradoxe : je ressens l'horreur et, en même temps, je suis rassurée.

8 De nos jours, la ville n'est point ténébreuse. D'innombrables réverbères et enseignes au néon illuminent la nuit. Les ténèbres, expulsées de la ville, sont devenues encore plus profondes : elles siègent au fond de nos cœurs.

9 Pour détourner le regard des ténèbres qui vivent au fond de nos cœurs, nous sortons dans la nuit de la ville sans ténèbres et allons nous enfermer dans un bar à karaoké. Ou bien, bras et jambes recroquevillés sous la chaufferette, nous musardons en regardant des feuilletons sentimentaux à l'eau de rose ou les défilés de thrillers morbides qui passent à la télévision. Les images ensanglantées de victimes de guerre ou de terrorisme se succèdent, nous ne cessons de manger des chips. Il n'y a pas de ténèbres dans le téléviseur, nous pouvons regarder en toute sécurité.

C'est terrifiant de scruter le tréfonds de son cœur.

11 Si nous pouvions rester anonyme pour toujours, et si en notre âme ne subsistait nulle empreinte, nous commettrions tous des actes interdits par la loi : vol, viol, incendie, meurtre.

12 Mais je ne crois pas qu'il n'y ait, plongées au fond du cœur humain, que des choses odieuses et laides. Dans la vie réelle tributaire du temps, il doit sûrement exister de douces et belles choses dont on ne se souvient pas et qui se trouvent au sein de ces ténèbres.

On dit que dans le monde islamique il y a ce qu'on appelle "la nuit dans la nuit », qui ouvre grande la porte du Ciel et rend douce l'eau d'un vase. Dans les ténèbres du théâtre, je peux lire des lettres écrites en une page de mon cœur, que la gomme ne peut effacer.

Les ténèbres du théâtre appartiennent à « la nuit dans la nuit ». 